\title{
Desain Hotel Lumbung Cottages 1 Gili Trawangan dengan Konsep Eksplorasi Kebudayaan Suku Sasak
}

\author{
Anggrita Yusanti dan Anggri Indraprasti \\ Departemen Desain Interior, Fakultas Arsitektur, Desain, dan Perencanaan, Institut Teknologi Sepuluh \\ Nopember (ITS) \\ e-mail: indraprasti@yahoo.com
}

\begin{abstract}
Abstrak-Indonesia adalah negara yang sangat indah di Asia. Hal ini dikenal sebagai negara kepulauan yang terdiri ribuan pulau indah. Berdasarkan situs lonely planet, salah satu pulau yang paling banyak dikunjungi di Indonesia setelah Bali dan Flores adalah Pulau Lombok. Pemerintah Indonesia telah memperluas rute internasional ke Bandara Internasional Lombok pada tahun 2017, berdasarkan halaman instagram resmi mereka pada bulan Juli 2017. Ketika para pengunjung ke Pulau Lombok berkembang, sektor bisnis akomodasi juga tumbuh lebih cepat. Salah satu pelaku bisnis akomodasi adalah hotel Lumbung Cottages 1 yang terletak di Gili Trawangan. Hotel ini memiliki 15 kamar unik yang terinspirasi oleh arsitektur tradisional di Pulau Lombok yang disebut unit lumbung. Hotel ini juga memiliki 2 unit vila untuk pengunjung keluarga. Fasilitas tambahan hotel terdiri dari kolam renang dan area lounge mini yang disebut beruga. Visi hotel kembali ke alam dan memiliki misi untuk melayani akomodasi yang sesuai dengan segala jenis wisatawan. Peralatan dari metode desain didasarkan pada pelestarian di hotel yang ada, wawancara dengan manajer hotel, dan studi pustaka. Berdasarkan data wawancara dan observasi, sebagian besar wisatawan di Gili Trawangan berasal dari backpacker muda, pasangan suami istri, dan keluarga. Dan segmentasi pengunjung hotel kebanyakan berasal dari backpacker muda dan pasangan suami istri. Kebanyakan dari mereka menyukai unit ruang lumbung, dari gaya unik dan material arsitektural alami. Konsep disain yang dipilih adalah "heritage exploration of Sasak Tribe" karena hotel ini berada pada interpretasi dari penglihatan hotel. Berdasarkan segmentasi visitir yang kebanyakan datang, hotel ini perlu untuk melayani tipe kamar mewah di unit vila mereka untuk mengaktualisasikan misi hotel. Konsep disain sekunder untuk memudahkan tamu hotel merancang lobby hotel dan area lounge.
\end{abstract}

Kata Kunci-Pulau Lombok, Segmentasi Wisata, Konsep Desain Hotel.

\section{PENDAHULUAN}

$\mathrm{D}$ EWASA ini khususnya pada era globalisasi, desain interior menjadi sebuah kebutuhan primer dalam menentukan standar dan kualitas dalam keseharian manusia. Atas latar belakang kebutuhan primer tersebut, desain interior menjadi komponen penting dalam dunia bisnis bangunan komersil. Salah satu contoh bangunan komersil yang banyak dijumpai adalah perhotelan. Aspek kualitas estetika serta kenyamanan interior pada fasilitas hotel merupakan aspek terpenting dalam menentukan standarkualitas dan kelas suatu hotel.

Bangunan bisnis komersil tersebut sering kali dijumpai pada lokasi-lokasi wisata. Salah satu daerah unggulan pariwisata Indonesia adalah Pulau Lombok. Berdasarkan informasi yang diperoleh dari akun instagram resmi

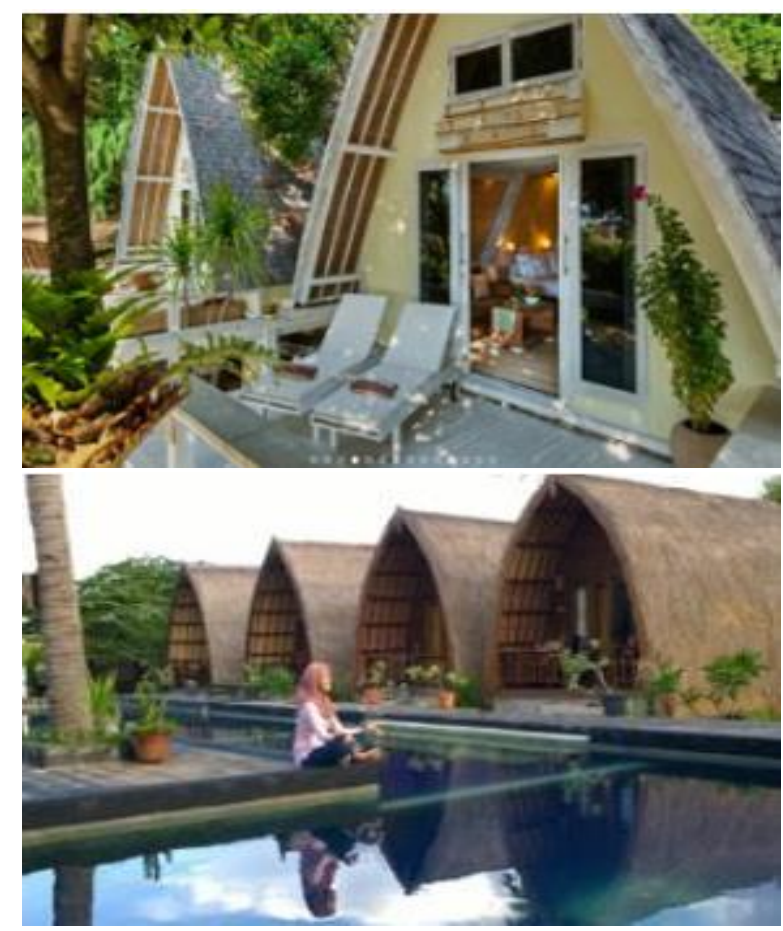

Gambar 1. Unit lumbung modern \& tradisional

Sumber: pearloftrawangan.com \& penulis

kementrian pariwisata Indonesia (@kemenpar) yang diakses pada 11 April 2017, Bapak mentri Pariwisata Indonesia, Dr. Ir. Arief Yahya, M.Sc, melakukan persetujuan dengan Lee Kuang, vice president maskapai Korea "JinAir" untuk melayani rute internasional menuju Pulau Lombok [1]. Selain itu untuk rute domestik, pada akhir tahun 2016 perusahaan kapal ferry Indonesia membuka rute pelayaran baru Surabaya menuju Lombok.

Hal tersebut memberikan dampak positif bagi pelaku bisnis akomodasi perhotelan di Lombok untuk menampung jumlah wisatawan yang melonjak. Salah satu daerah wisata di Lombok yang memiliki minat kunjungan wisatwan terbanyak adalah Gili Trawangan, salah satu pulau kecil di Desa Gili Indah. Gili Indah merupakan objek wisata yang terdiri atas gugusan 3 pulau kecil diantaranya Gili Trawangan, Gili Air, dan Gili Meno. Lokasi ketiga gili tersebut terletak di sisi barat laut Pulau Lombok, Kabupaten Lombok Utara, Provinsi NTB.

Untuk menuju Gili Trawangan, perjalanan yang ditempuh cukup panjang. Bermula dari bandar udara Lombok International Airport, wisatawan menempuh jalur darat menggunakan bis umum menuju pelabuhan Bangsal. Sesampainya di pelabuhan Bangsal, wisatawan dapat membeli tiket kapal penyeberangan menuju Gili Trawangan. 


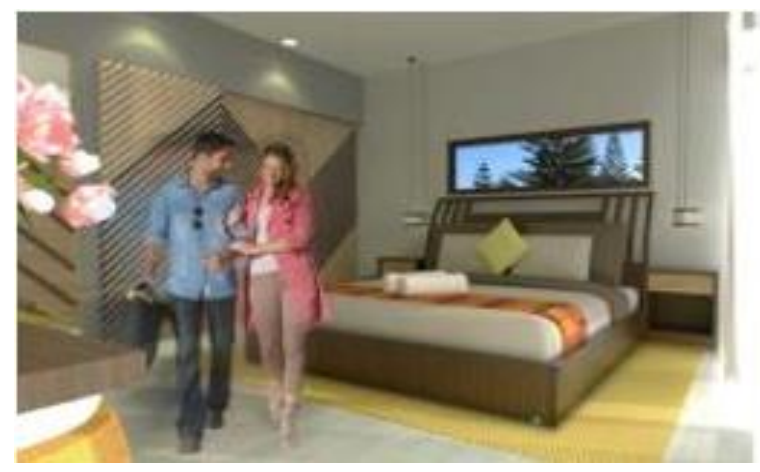

Gambar 2. Kamar tidur unit vila tipe single.

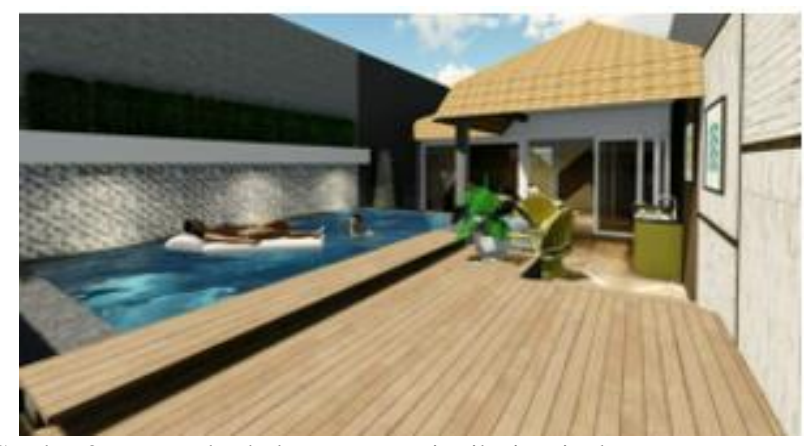

Gambar 3. Pantry dan kolam renang unit vila tipesingle.

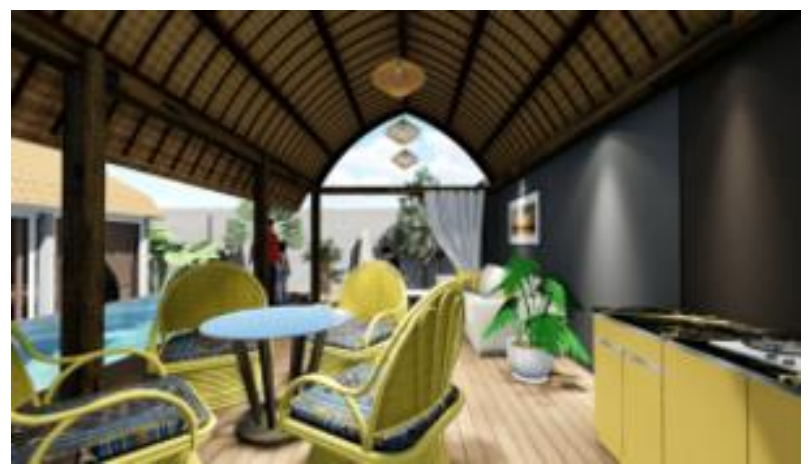

Gambar 4. Pantry unit vila tipe master.

Salah satu pelaku bis nis perhotelan di Gili Trawangan yang diangkat menjadi objek desain adalah hotel Lumbung Cottages 1 Gili Trawangan. Hotel tersebut merupakan jenis hotel independen, yang didirikan diatas lahan yang semula seluas $2000 \mathrm{~km}^{2}$ menjadi $3226 \mathrm{~km}^{2}$ dari tahun 2006 hingga saat ini (tahun 2017). Seiring dengan berkembangnya lahan hotel, fasilitas yang dimiliki hotelpun kian menarik. Fasilitas tesebut diantaranya unit kamar tipe lumbung dan vila (rumah bata), receptionist, serta kolam renang yang dilengkapi area santai.

Rumah adat lumbung yang diaplikasikan menjadi salah satu tipe unit kamar hotel merupakan salah satu kekayaan budaya lokal milik Suku Sasak di Pulau Lombok [2][3]. Kebudayaan yang dimiliki Suku Sasaks angat berlimpah akan nilai filosofi dan estetikanya. Selain kebudayaan bangunan adat lumbung padi yang unik, kain tenun dan kain lurik produksi lokal kian menjadi daya tarik wisatawan untuk mengunjungi lombok [4][5].

Bangunan adat lumbung padi merupakan konsep desain unggulan yang diterapkan pada hotel Lumbung Cottages 1 untuk menarik pengunjung. Berangkat dari konsep arsitektur eksisting hotel yakni bangunan adat lumbung padi sebagai unit kamar hotel dominan, maka hotel membutuhkan konsep pelengkap yang dapat menghidupkan visi back to nature. Konsep pelengkap tersebut yakni kain tenun dan kain lurik
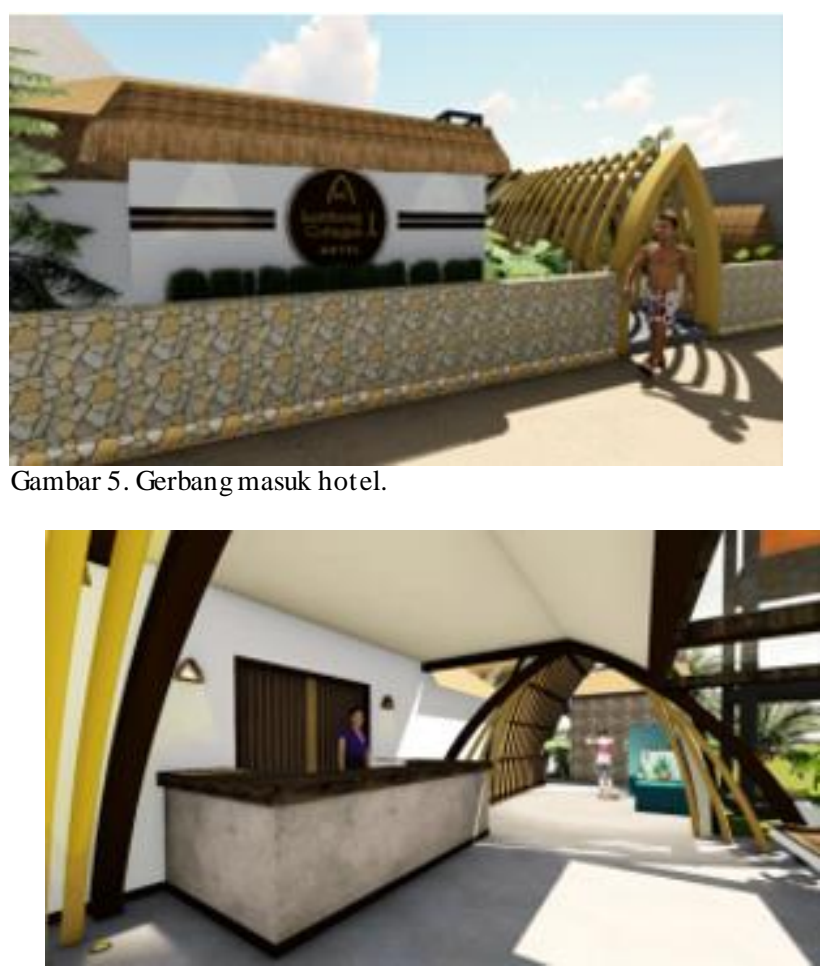

Gambar 6. Area lobby dengan resepsionis hotel.

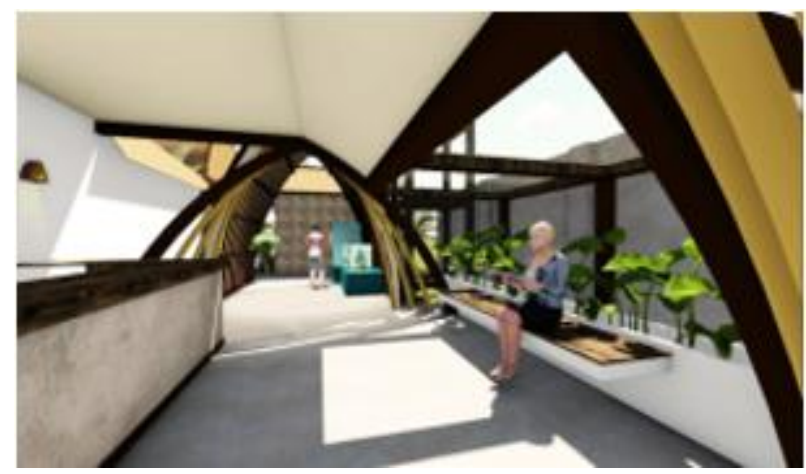

Gambar 7. Area tunggu pada lobby hotel.

khas Lombok yang dipadukan dengan nuansa tropis, untuk diaplikasikan pada desain interior vila, lobby, dan lounge hotel.

Walaupun termasuk pulau mikro, Gili Trawangan memiliki lebih dari 200 jenis penginapan [5]. Sebagian besar jenis penginapan di Gili Trawangan tersebut memiliki bentuk bangunan yang menyerupai lumbung padi, yakni bangunan adat Suku Sasak. (Gambar 1)

Konsep yang diaplikasikan pada mayoritas hotel di Gili Trawangan adalah hasil transformasi desain lumbung padi yang lebih condong kepada konsep mewah dan modern, yakni menggunakan warna kontemporer serta dominasi material non-alami. Namun berbeda dengan konsep pada hotel Lumbung Cottages 1 yang menerapkan konsep tradisional seutuhnya pada unit kamar tipe lumbung dengan menggunakan material alami seutuhnya serta konsep warna bangunan yang kental dengan tema tradisional.

Menerapkan konsep tradisional pada unit kamar lumbung dengan tatanan cluster layaknya suatu desa Suku Sasak pada hotelLumbung Cottages 1 tersebut menarik banyak perhatian wisatawan. Selain unit kamar tipe lumbung, hotel menyediakan 2 unit kamar vila. Namun wisatawan yang berminat tak sebanyak unit kamar lumbung. Sehingga unit vila tersebut memerlukan rancangan desain interior agar dapat menyeimbangi peminat unit kamar lumbung. 


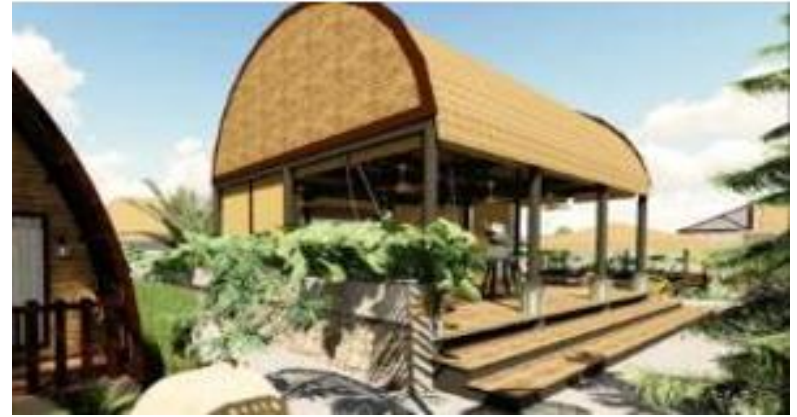

Gambar 8. T ampak depan bangunan lounge hotel.

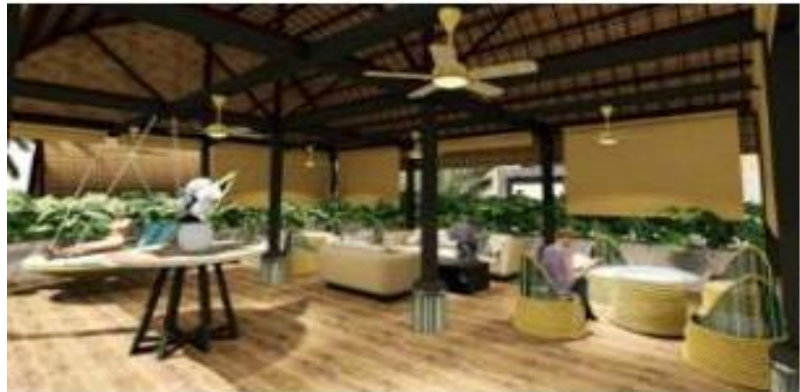

Gambar 9. Area lounge hotel.

Selain merancang desain interior unit kamar vila, hotel Lumbung Cottages 1 membutuhkan fasilitas lobby dan area lounge bagi tamu hotel. Fasilitas lobby merupakan fasilitas krusial bagi hotel. Lobby adalah area interaksi pertama antara tamu hotel dengan pegawai hotel. Sehingga penting untuk menerapkan desain interior terkonsep untuk memberikan kesan pertama terbaik untuk tamu hotel. Selanjutnya adalah fasilitas yang lounge memiliki peranan penting sebagai area berkumpul dan bersosialisasi bagi tamu hotel. Sama halnya dengan area lobby sebagai area umum, penerapan konsep desain interior pada area lounge baiknya diperhatikan. Agar tamu hotel menikmati seluruh fasilitas hotel dengan sepenuh hati dan tak ragu untuk kembali meluangkan waktu berlibur di hotel ters ebut.

\section{METODE RISET}

Metode yang digunakan dalam merancang desain hotel Lumbung Cottages 1 antara lain dengan melaksanakan survey lokasi eksisting dan observasi dengan melakukan studipartisipan sebagaitamu hotel. Kemudian melaksanakan wawancara dengan manajer hotel dan metode studipustaka.

\section{PEMBAHASAN}

\section{A. Kajian Eksisting}

Hotel Lumbung Cottages 1 didirikan pada tahun 2006. Disusul pada tahun 2016, hotel tersebut melebarkan area penginapan dengan membangun hotel Lumbung Cottages 2 yang berlokasi terpisah dengan hotel Lumbung Cottages 1, sejauh kurang lebih 200 meter ke arah barat pulau. Hotel Lumbung Cottages memiliki visi back to nature dan memiliki misi sebagai penyedia tempat penginapan yang mudah dijangkau oleh wisatawan lokal dan internasional dari berbagai jenisnya. Berdasarkan hasil wawancara, sebagian besar wisatawan domestik dan internasional yang berlibur ke Gili Trawangan dapat diurutkan menjadi 3 segmen. Urutan segmen dengan jumlah terbesar adalah kelompok anak muda, kemudian disusul dengan pasangan muda, dan yang terakhir adalah keluarga. Fasilitas-fasilitas yang terdapat pada hotel

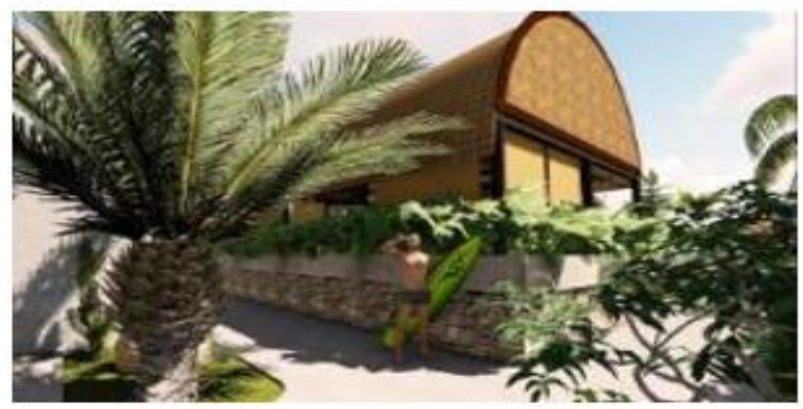

Gambar 10. Tampak belakang bangunan lounge hotel.

Lumbung Cottages 1 dapat dibagi menjadi 2 tipe area, yaitu area indoor dan area outdoor. Area indoor sebagian besar merupakan area khusus yang memiliki nilai privasi tinggi. Area indoor pada hotel tersebut ialah berupa unit kamar lumbung, unit kamar villa, ruang staff dan dapur hotel. Kemudian area outdoor didominasi oleh area dengan tingkat privasi rendah antar penghuni didalam hotel. Fasilitasfasilitas yang terdapat dalam area outdoor tersebut antara lain berupa gerbang masuk hotel, area receptionist, area kolam renang, dan beruga.

Lumbung Cottages Hotel termasuk dalam kategori independent hotel yang dikelola langsung oleh keluarga pemilik hotel. Sistem marketing hotel dilakukan dengan 2 cara yakni melalui sistem online dengan menjalin kerjasama bersama agen travel online, dan sistem marketing langsung dengan menawarkan secara langsung kepada wisatawan yang baru tiba di pelabuhan Gili Trawangan. Hasil dari penawaran on the spot di pelabuhan merupakan sistem andalan hotel. Sistematika bagi tamu yang hendak menginap di hotel Lumbung Cottages ialah dengan melakukan reservasi online melalui agen travel yang bekerja sama dengan hotel. Bagi tamu yang telah reservasi online, dapat dijemput oleh pegawai menuju hotel dan melakukan transaksi terlebih dahulu di receptionist hotel. Bagi tamu yang tidak melakukan reservasi online, dapat mengunjungi receptionist hotel untuk melakukan transaksi. Setelah melakukan transaksi, tamu dapat menikmati fasilitas yang terdapat pada hotel. Hotel Lumbung Cottages menerapkan sistem continental plan, dimana tamu hanya mendapatkan pelayanan sarapan pagidari hotel.

Berdasarkan hasil observasi, hotel memerlukan beberapa rancangan desain yang dapat memvisualis as ikan visi dan mis $i$ hotel, yakni mendesain kembali layout denah (prosentase sebanyak 22\% dalam mengubah bangunan eksisting di bagian utara) hotel Lumbung Cottages 1 dengan menambahkan beberapa area servis berupa lobby dan lounge dengan tipe semi-outdoor pada kedua fasilitas tersebut. Area lounge dibangun diatas lahan kosong yang terletak di tengah hotel dan tepat didepan kolam renang. Sementara lobby hotel diletakkan pada sisi utara hotel, menghadap jalan protokol Gili Trawangan. Kemudian mendesain ulang interior unit kamar vila sesuai dengan segmen pengguna tipe keluarga dan kelompok anak muda, disertai unsur efisiensi fasilitas pengguna, efektivitas sirkulasi gerak, dan estetika elemen interior yang sesuai dengan konsep desain eksplorasi kebudayaan Suku Sasak.

\section{B. Konsep Makro}

Konsep desain pada hotel Lumbung Cottages 1 Gili Trawangan merupakan korelasi kebutuhan pengguna hotel, baik dari hasil interview pemilik hotel maupun survey bangunan serta segmentasi pengunjung Gili Trawangan. 
Konsep eksplorasi kebudayaan Suku Sasak merupakan konsep yang tepat dalam merevitalisasi desain hotel karena memiliki korelasi dengan visi hotel dan sesuai dengan nama hotel yakni Lumbung Cottages. Dari beragam hasil kebudayaan yang dimiliki oleh Suku Sasak, bangunan adat lumbung padi merupakan kebudayaan yang terlebih dahulu diaplikasikan pada salah satu tipe unit kamar pada eksisting hotel. Sehingga untuk memperkuat konsep kebudayaan Suku Sasak sebelumnya serta menghidupkan visi hotel yakni back to nature, hasil budaya berupa kain tenun rang-rang dan tenun lurik yang dipadukan dengan nuansa tropis pedesaan Suku Sasak, menjadi fokus konsep yang dipadukan dengan bangunan adat lumbung padi Suku Sasak.

\section{Konsep Mikro}

Konsep mikro yang diaplikasikan pada dinding area terpilih hotel dibagi menjadi 2 jenis, yaitu semi terbuka dan tertutup. Pengaplikasian dinding semi terbuka diharapkan dapat memasukkan unsur outdoor kedalam ruangan. Sedangkan dinding tertutup diaplikasikan pada area unit kamar vila untuk meningkatkan privasi. Kemudian konsep lantai yang diaplikasikan didominasi oleh material WPC (Wood Plastic Composite) merk DUMA, yang lebih unggul dari penggunaan kayu alami.

Penggunaan plafond berbeda-beda pada tiap area hotel, sebagian besar yang beratapkan lumbung mengaplikasikan plafond ekspos. Kemudian implementasi konsep warna yang hangat dan natural seperti hijau, coklat, krem, abu-abu, putih, berdampingan sempurna dengan visi hotel untuk mewujudkan konsep desain. Eksplorasi furniture yang diterapkan terinspirasi dari atap lumbung yang dipadukan dengan keindahan tenun lombok, dalam menghasilkan kursi rotan yang tepat.

\section{HASIL DESAIN}

\section{A. Area Unit Kamar Vila}

Area Unit Kamar ditunjukkan pada Gambar 2, 3 dan 4.

B. Area Lobby

Area Lobby Villa ditunjukkan pada Gambar 5, 6 dan 7 .

\section{Area Lounge}

Area Lounge ditunjukkan pada Gambar 8, 9 dan 10.

\section{KESIMPULAN}

\section{A. Kesimpulan}

Yang dapat disimpulkan dari rancangan desain hotel Lumbung Cottages 1 Gili Trawangan tersebut adalah terciptanya korelasi antara konsep eksplorasi kebudayaan Suku Sasak dengan hasil survey, wawancara, studi partisipan yang dilaksanakan pada eksisting hotel. Kemudian terwujudnya korelasi konsep desain dengan misi hotel yakni tersedianya penginapan bagi semua segmen dan jenis wisawatan. Dengan menghadirkan unit kamar vila yang memiliki fasilitas ekstra, diharapkan dapat menyeimbangi peminat unit kamar lumbung terhadap unit vila.

Kesimpulan ketiga adalah mendesain rancangan area lobby, dengan mencerminkan konsep dan identitas hotelpada pengaplikasian atap yang berbentuk seperti atap lumbung. Kemudian terciptanya ruang sosialisasi dengan merencanakan rancangan desain lounge yang diletakkan tepat didepan area kolam renang hotel.

\section{B. Saran}

Saran yang dapat diberikan dari rancangan desain hotel berikut adalah perlunya penilitan yang lebih lanjut terhadap nilai anthropometri dan ergonomi pada elemen interior.

\section{DAFTAR PUSTAKA}

[1] Kementrian Pariwisata, "Rute penerbangan internasional menuju Pulau Lombok."

[2] Departemen Pendidikan dan Kebudayaan, "Sejarah Daerah Nusa Tenggara Barat,"Jakarta, 1978.

[3] A. Arismunandar and et al, Indonesian Heritage: Arsitektur (Edisi Bahasa Indonesia). Jakarta: Buku Antar Bangsa, 2002.

[4] J. Fischer, Threads of Tradition: Textiles of Indonesia and Sarawak. Berkeley: University of CaliforniaPress, 1979.

[5] L. Turangan, Seni Budaya dan Warisan Indonesia. Jakarta: PT Aku Bisa, 2014. 